\title{
Banco de Sementes e Flora Emergente de Plantas Daninhas
}

\author{
Seed Bank and Abovegroud Weed
}

ISAAC, R.A. ${ }^{2}$ e GUIMARÃES, S.C. ${ }^{3}$

\begin{abstract}
RESUMO - Com o objetivo estudar a relação existente entre o banco de sementes e o posterior estabelecimento da flora emergente de plantas daninhas, sob sistema de semeadura direta e convencional, realizou-se uma pesquisa no municipio de Pedra PretaMT. O banco de sementes e a flora emergente foram avaliados, em cada sistema de cultivo, em 50 células contíguas de $1 \mathrm{~m}^{2}$. O banco de sementes foi determinado a partir de amostras de $2,4 \%$ da área de cada célula na profundidade de $0-5 \mathrm{~cm}$, em setembro de 2003, por meio da técnica de flotação. A flora emergente foi avaliada por meio de seis levantamentos sucessivos, até novembro de 2004, realizados na área total de cada célula, com retirada dos indivíduos após cada avaliação. Esses dados foram utilizados para calcular os parâmetros fitossociológicos e também a correlação entre o banco de sementes e a flora emergente. A similaridade entre o banco de sementes e a flora emergente foi baixa tanto no sistema de semeadura direta quanto no convencional. Houve correlação significativa apenas para Amaranthus deflexus e Eleusine indica entre o banco de sementes e a flora emergente. Para A. deflexus a correlação foi significativa nos dois sistemas de semeadura e, para E. indica, somente para semeadura direta.
\end{abstract}

Palavras-chave: Amaranthus deflexus, correlação, fitossociologia.

\begin{abstract}
A study was carried out in Pedra Petra-MT aiming to study the relation between seed bank and posterior aboveground weed in annual crop fields under no-till and tillage systems. The seed bank and weed flora were assessed in fifty contiguous $1 \mathrm{~m}^{2}$ cells, under both cultivation systems. The seed bank was determined from soil samples from $4 \%$ of the area of each cell at 0 $5 \mathrm{~cm}$ depth using the flotation technique. The aboveground weed vegetation was evaluated by six successive surveys until November 2004, carried out in the total area of each cell, with removal of the individuals from the area after each evaluation. These data were used to calculate the phytosociological parameters and the correlation between the seed bank and aboveground weed. The similarity between the bank seed and the aboveground vegetation was low for both systems. Only Amaranthus deflexus and Eleusine indica showed to have significant correlation between bank seeds and the aboveground weed vegetation. For $\boldsymbol{A}$. deflexus, the correlation was significant in both cultivation systems, while for $\boldsymbol{E}$. indica, only under no-till.
\end{abstract}

Keywords: Amaranthus deflexus, correlation, phytosociology.

1 Recebido para publicação em 21.10.2007 e na forma revisada em 29.5.2008.

Parte da dissertação de mestrado em Agricultura Tropical do primeiro autor apresentada à Faculdade de Agronomia e Medicina

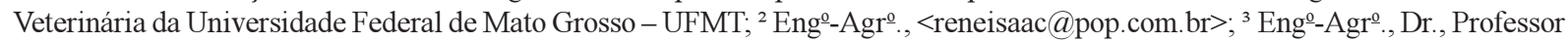
da Faculdade de Agronomia e Medicina Veterinária - UFMT, Avenida Fernando Corrêa da Costa, s/n, 78060-900 Cuiabá-MT, <sheep@cpd.ufmt.br> 


\section{INTRODUÇÃO}

Em agroecossistemas constantemente perturbados, como em lavouras de culturas anuais, as plantas daninhas conseguem permanecer e perpetuar em razão de vantagens competitivas, que, entre outras, estão diretamente relacionadas às reservas de sementes viáveis dessas espécies presentes no solo.

Os agroecossistemas sob cerrado, responsáveis por grande parte da produção brasileira de grãos e com alto índice de rendimento agronômico, têm como uma de suas características sistemas de cultivo com elevado uso de insumos, como corretivos, fertilizantes e pesticidas. A redução no uso de pesticidas, por meio das táticas de manejo de pragas, doenças e plantas daninhas, requer conhecimento sobre a dinâmica da infestação dos organismos-alvo, informações que, na área de plantas daninhas, são muito escassas no que se refere ao entendimento da dinâmica que correlaciona o banco de sementes e sua flora emergente.

O banco de sementes de plantas daninhas no solo vem sendo utilizado para pesquisar as relações quantitativas entre sua população e a flora infestante (Granatos \& Torres, 1993). A dinâmica de uma população de sementes no solo é resultante do balanço entre o ingresso de indivíduos por produção e dispersão e o egresso de outros (Carmona, 1992; Martins \& Silva, 1994); as entradas e saídas do banco de sementes controlam de forma direta a densidade, composição florística e reserva genética das espécies em uma comunidade (AlmeidaCortez, 2004).

A dinâmica populacional de plantas daninhas refere-se a mudanças na composição da comunidade infestante no tempo, considerando o número e a dominância relativa de cada espécie no agroecossistema (Zelaya et al., 1997). Análises de populações florísticas permitem deduções quanto ao dinamismo, composição e tendências futuras, bem como o conhecimento das relações existentes entre as comunidades e seu habitat (Lamprecht, 1990).

Assim, o conhecimento da correlação entre as sementes de plantas daninhas no banco do solo e o estabelecimento da respectiva flora emergente e seu potencial de infestação resulta numa valiosa ferramenta para a previsão de infestações, possibilitando, conseqüentemente, a proposição de programas mais eficientes de manejo das plantas daninhas em áreas de culturas.

A presente pesquisa objetivou caracterizar o banco de sementes e a flora emergente de plantas daninhas em culturas anuais, sob os sistemas de semeadura direta e convencional, além de estudar a correlação entre estes.

\section{MATERIAL E MÉTODOS}

A pesquisa foi realizada na fazenda Farroupilha, pertencente à empresa Petrovina Sementes, localizada no município de Pedra Preta, região sul do Estado de Mato Grosso, a $732 \mathrm{~m}$ de altitude $\left(16^{\circ} 51^{\prime} 21^{\prime \prime}\right.$ de latitude sul e $54^{\circ} 03^{\prime} 50^{\prime}$ de longitude oeste). A escolha do local de estudo levou em consideração o fato de a propriedade possuir talhões sob o sistema de semeadura direta com mais de cinco anos, e talhões próximos sob sistema de semeadura convencional. Nos talhões sob semeadura direta, a soja foi a principal cultura cultivada nas últimas seis safras, sendo o milheto cultivado na "safrinha". Nos talhões sob semeadura convencional foi cultivado o algodão como monocultura, no mesmo período.

A área de estudo consistiu de duas malhas de $50 \mathrm{~m}^{2}(5 \times 10 \mathrm{~m})$, uma em área sob semeadura direta e outra sob semeadura convencional. Cada malha foi dividida em 50 células de $1 \mathrm{~m}^{2}$. Os vértices de cada malha foram demarcados com estacas de madeira, e sua respectiva divisão em células teve seus limites estabelecidos com barbante de algodão. Os talhões estudados para os sistemas de semeadura direta e convencional encontram-se separados por um carreador.

A amostragem do solo para determinação do banco de sementes foi realizada no mês de setembro de 2003, utilizando-se trado tipo sonda, de anel cilindrico com dimensões de $5 \mathrm{~cm}$ de diâmetro e $5 \mathrm{~cm}$ de altura, fornecendo um volume de $98,2 \mathrm{~cm}^{3}$. Foram coletadas 12 subamostras por célula, totalizando $2,4 \%$ de sua área, na profundidade de $0-5 \mathrm{~cm}$, perfazendo uma amostra composta de aproximadamente $1,5 \mathrm{~kg}$ de solo. Essas amostras encontravamse secas por ocasião da coleta e foram 
acondicionadas em sacos plásticos, os quais foram etiquetados e identificados com a numeração de sua respectiva célula. Logo após, foram transportadas e armazenadas em ambiente de sala até o uso, em maio de 2004.

Estimativa do banco de sementes - As amostras de solo de cada célula foram destorroadas, peneiradas e homogeneizadas. Delas se extraiu uma alíquota de $100 \mathrm{~g}$, que foi lavada com água sob ducha de torneira para retirada das frações mais finas do solo, dentro de peneiras de latão, com malhas de aço inox de $0,3 \mathrm{~mm}$ (ABNT 50). A fração resultante, composta por partículas mais grossas do solo (areia), sementes de plantas daninhas, palhas e restos vegetais, foi seca em estufa a $80{ }^{\circ} \mathrm{C}$ por 40 minutos. Após a secagem, procedeu-se à separação das sementes do solo por meio da flotação, realizada em solução saturada de $\mathrm{CaCl}_{2} \cdot 2 \mathrm{H}_{2} \mathrm{O}$, com densidade de 1,40-1,42 $\mathrm{g} \mathrm{cm}^{-3}$, controlada com densimetro. O processo consistiu em transferir $100 \mathrm{~mL}$ da solução de $\mathrm{CaCl}_{2} \cdot 2 \mathrm{H}_{2} \mathrm{O}$ para proveta de $250 \mathrm{~mL}$ de capacidade, que tinha previamente recebido a amostra seca obtida na etapa anterior. O conjunto foi agitado por cinco minutos, sendo deixado posteriormente para decantar. O sobrenadante foi então vertido sobre a peneira, obtendo-se as sementes de plantas daninhas flotadas e impurezas (restos vegetais, palhas etc.). Esse material foi lavado com água sob ducha de torneira, na própria peneira, e o conjunto, seco em estufa a $80^{\circ} \mathrm{C}$. Após secagem, as sementes foram acondicionadas em saco de papel, sendo posteriormente separadas, identificadas e contadas sob microscópio estereoscópico. Na identificação das espécies utilizaram-se as obras de Kissmann \& Groth $(1997,1999,2000)$ e Lorenzi et al. (2000). Para certificação da viabilidade, foi utilizado o teste da "pressão ao toque", com pinça, considerando-se como viáveis as sementes firmes. As sementes quebradas e/ou chochas foram consideradas não-viáveis.

Levantamento floristico - O estudo da flora emergente foi feito nas mesmas células utilizadas para a amostragem de solo na determinação do banco de sementes.

Foram realizadas seis avaliações da flora emergente, em 1 de dezembro de 2003 (fluxo 1), 20 de janeiro de 2004 (fluxo 2), 2 de março de 2004 (fluxo 3), 5 de maio de 2004 (fluxo 4), 9 de junho de 2004 (fluxo 5) e 12 de novembro de 2004 (fluxo 6). Nas avaliações, foram identificadas e contadas todas as espécies de plantas daninhas presentes em cada célula, a fim de obter o número de indivíduos por espécie. Em cada avaliação, logo após o levantamento da flora emergente, as plantas eram eliminadas, para que não houvesse qualquer influência nos levantamentos subseqüentes.

Com os dados de cada espécie, foram calculadas a freqüência, a densidade e a abundância, absolutas e relativas, além do índice de valor de importância (IVI) (Pitelli, 2000). A similaridade florística entre as áreas amostradas foi avaliada pelo indice de Sørensen (Booth et al., 2003), verificando-se também as correlações entre o banco de sementes e a flora emergente, optando-se pela correlação de Spearman, por ser mais apropriada para dados que não possuem distribuição normal (Steel \& Torrie, 1980; Cardina et al., 1996).

\section{RESULTADOS E DISCUSSÃO}

\section{Semeadura direta (SSD)}

Banco de sementes (SSD) - Nas amostras do sistema de semeadura direta foram encontradas nove espécies distribuídas em cinco familias, das quais cinco Monocotyledoneae (todas Poaceae) e quatro Dicotyledoneae. As espécies encontradas nas amostras de solo e as respectivas nomenclaturas estão apresentadas na Tabela 1 . Os resultados dos índices fitossociológicos estão apresentados na Tabela 3.

Pennisetum americanum foi a mais importante, seguida de Brassica rapa, Amaranthus deflexus, Digitaria horizontalis, Cenchrus echinatus e Eleusine indica. A espécie Pennisetum americanum destacou-se no banco de sementes do sistema de semeadura direta, com densidade de 2.028 sementes por $\mathrm{m}^{2}$, muito superior à segunda espécie mais importante; além disso, esteve presente em $80 \%$ das amostras. Apesar de sua importância nas amostras, há de se considerar que $P$. americanum é uma espécie cultivada neste sistema de sucessão, contribuindo "artificialmente" na análise do banco de sementes do solo. 
Tabela 1 - Relação das espécies encontradas no banco de sementes, em amostras coletadas nos sistemas de semeadura direta e convencional

\begin{tabular}{|c|c|c|c|c|}
\hline Classe $^{\mathrm{1}^{-}}$ & Família/nome científico & Nome vulgar & $\mathrm{SSD}^{2 /}$ & $\mathrm{SSC}^{-3 /}$ \\
\hline & Amaranthaceæ & & & \\
\hline \multirow[t]{2}{*}{ Dic } & Amaranthus deflexus L. & Caruru & $\mathrm{X}$ & $\mathrm{X}$ \\
\hline & Commelinaceæ & & & \\
\hline \multirow[t]{2}{*}{ Mon } & Commelina benghalensis L. & Trapoeraba & & $\mathrm{X}$ \\
\hline & Brassicaceæ & & & \\
\hline \multirow[t]{2}{*}{ Dic } & Brassica rapa $\mathrm{L}$. & Mostarda & $\mathrm{X}$ & $\mathrm{X}$ \\
\hline & Fabaceæ & & & \\
\hline \multirow[t]{2}{*}{ Dic } & Mimosa pigra $\mathrm{L}$. & Mimosa & $\mathrm{X}$ & \\
\hline & Oxalidaceæ & & & \\
\hline \multirow[t]{2}{*}{ Dic } & Oxalis corniculata L. & Azedinha & $\mathrm{X}$ & \\
\hline & Роасеæ & & & \\
\hline Mon & Cenchrus echinatus L. & Capim-carrapicho & $\mathrm{X}$ & \\
\hline Mon & Digitaria horizontalis Wild. & Capim-colchão & $\mathrm{X}$ & \\
\hline Mon & Eleusine indica (L.) Gaertn & Capim-pé-de-galinha & $\mathrm{X}$ & \\
\hline Mon & Pennisetum americanum (L.) Leeke/K. Schum. & Milheto & $\mathrm{X}$ & \\
\hline \multirow[t]{2}{*}{ Mon } & Rhynchelytrum repens (Willd.) C.E. Hubb. & Capim-favorito & $\mathrm{X}$ & \\
\hline & Portulacaceæ & & & \\
\hline Dic & Portulaca oleracea L. & Beldroega & & $\mathrm{X}$ \\
\hline
\end{tabular}

1/ Mon - Monocotyledoneae. Dic - Dicotyledoneae.

2/ SSD - sistema de semeadura direta. ${ }^{3}$ SSC - sistema de semeadura convencional

Flora emergente (SSD) - Na malha sob sistema de semeadura direta foram encontradas 19 espécies diferentes, distribuídas em 10 famílias, das quais 14 eram Dicotyledoneae e 5 Monocotyledoneae (Tabela 2). As famílias que apresentaram maior número de espécies foram: Poaceae (4), Asteraceae (3) e Euphorbiaceae (3). Os resultados dos índices fitossociológicos calculados estão apresentados na Tabela 4 .

Na malha sob sistema de semeadura direta, foi contabilizada a emergência de 5.012 plantas daninhas, o que corresponde à densidade média de 100,24 plantas por $\mathrm{m}^{2}$. O maior fluxo de emergência das espécies, tanto Monocotyledoneae como Dicotyledoneae, ocorreu nos meses de dezembro de 2003 (31,7 plantas por $\mathrm{m}^{2}$, representando $31,64 \%$ das emergências) e novembro de 2004 (41,8 plantas por $\mathrm{m}^{2}$, representando $41,72 \%$ das emergências). As espécies Monocotyledoneae ocorreram em maior número em todas as avaliações, com densidade, no período, de 82,9 plantas por $\mathrm{m}^{2}$, o que corresponde a $82,8 \%$ do total de emergências verificadas na malha. Esses dados demográficos, representando os maiores fluxos de emergência das espécies de plantas daninhas nos meses de novembro e dezembro, coincidem com o início das principais precipitações pluviais, desencadeando maior germinação do banco de sementes e emergência das plantas. Pereira \& Velini (2003), avaliando os efeitos de sistemas de cultivo no cerrado sobre a dinâmica de populações de plantas daninhas, constataram que a maior quantidade de espécies daninhas ocorre devido às primeiras chuvas do ano agrícola. Blanco et al. (1994), analisando a distribuição mensal de emergência de plantas daninhas, também observaram que, devido às primeiras chuvas, em média, 70\% da emergência das plântulas resulta do primeiro fluxo de germinação das sementes.

Assim, ao longo do tempo, o decréscimo no número de plantas emergidas é mais acentuado que o número de sementes viáveis presentes no banco do solo, devido, principalmente, ao fato de estas sementes nem sempre 
Tabela 2 - Relação das espécies da flora emergente encontradas nos sistemas de semeadura direta e convencional

\begin{tabular}{|c|c|c|c|c|}
\hline Classe $^{{ }^{1 /}}$ & Família/nome científico & Nome vulgar & $\mathrm{SSD}^{2 /}$ & $\mathrm{SSC}^{-3 /}$ \\
\hline & Amaranthaceae & & & \\
\hline \multirow[t]{2}{*}{ Dic } & Amaranthus deflexus L. & Caruru & $\mathrm{X}$ & $\mathrm{X}$ \\
\hline & Asteraceae & & & \\
\hline Dic & Ageratum conyzoides $\mathrm{L}$. & Mentrasto & $\mathrm{X}$ & $\mathrm{X}$ \\
\hline Dic & Bidens pilosa $\mathrm{L}$. & Picão-preto & $\mathrm{X}$ & $\mathrm{X}$ \\
\hline \multirow[t]{2}{*}{ Dic } & Elephantopus mollis H.B.K. & Fumo-bravo & $\mathrm{X}$ & $\mathrm{X}$ \\
\hline & Commelinaceae & & & \\
\hline \multirow[t]{2}{*}{ Mon } & Commelina benghalensis L. & Trapoeraba & $\mathrm{X}$ & $\mathrm{X}$ \\
\hline & Asteraceæ & & & \\
\hline \multirow[t]{2}{*}{ Dic } & Tridax procumbens L. & Erva-de-touro & $\mathrm{X}$ & $\mathrm{X}$ \\
\hline & Convolvulaceae & & & \\
\hline \multirow[t]{2}{*}{ Dic } & Ipomoea triloba $\mathrm{L}$. & Corda-de-viola & $\mathrm{X}$ & $\mathrm{X}$ \\
\hline & Cyperaceae & & & \\
\hline \multirow[t]{2}{*}{ Dic } & Cyperus ferax Rich. & Junquinho & & $\mathrm{X}$ \\
\hline & Euphorbiaceae & & & \\
\hline Dic & Chamaesyce hirta (L.) Millsp. & Erva-de-santa-luzia & $\mathrm{X}$ & $\mathrm{X}$ \\
\hline Dic & Croton sp. & Cróton & $\mathrm{X}$ & \\
\hline \multirow[t]{2}{*}{ Dic } & Euphorbia heterophylla L. & Leiteira & $\mathrm{X}$ & $\mathrm{X}$ \\
\hline & Poaceae & & & \\
\hline Mon & Cenchrus echinatus L. & Capim-carrapicho & $\mathrm{X}$ & $\mathrm{X}$ \\
\hline Mon & Digitaria horizontalis Wild. & Capim-colchão & $\mathrm{X}$ & \\
\hline Mon & Eleusine indica (L.) Gaertn & Capim-pé-de-galinha & $\mathrm{X}$ & $\mathrm{X}$ \\
\hline \multirow[t]{2}{*}{ Mon } & Pennisetum americanum (L.) L./K. Schum. & Milheto & $\mathrm{X}$ & $\mathrm{X}$ \\
\hline & Portulacaceae & & & \\
\hline \multirow[t]{2}{*}{ Dic } & Portulaca oleracea L. & Beldroega & $\mathrm{X}$ & $\mathrm{X}$ \\
\hline & Rubiaceae & & & \\
\hline Dic & Diodia teres & Mata-pasto & $\mathrm{X}$ & \\
\hline \multirow[t]{2}{*}{ Dic } & Spermacoce latifolia Aubl. & Erva-quente & $\mathrm{X}$ & \\
\hline & Solanaceae & & & \\
\hline Dic & Nicandra physaloides (L.) Pers. & Joá-de-capote & $\mathrm{X}$ & \\
\hline Dic & Solanum americanum Mill. & Maria-pretinha & $\mathrm{X}$ & \\
\hline
\end{tabular}

1/ Mon - Monocotyledoneae. Dic - Dicotyledoneae.

2/ SSD - sistema de semeadura direta. ${ }^{3}$ SSC - sistema de semeadura convencional.

apresentarem vigor suficiente para germinar e dar origem a plântulas normais, com capacidade de sobrevivência (Roberts \& Feast, 1972).

As espécies mais importantes, considerando-se o indice de valor de importância, para o sistema de semeadura direta foram: Cenchrus echinatus, Pennisetum americanum, Eleusine indica, Chamaesyce hirta e Amaranthus deflexus.

\section{Correlações entre o banco de sementes e a flora emergente (SSD)}

Comparando a similaridade entre o banco de sementes e a flora emergente no sistema de semeadura direta, foram encontradas 23 espécies, das quais 19 ocorreram na flora emergente, sendo nove nas amostras do banco de sementes, e cinco foram comuns aos dois 
Tabela 3 - Parâmetros fitossociológicos das espécies de sementes encontradas nas amostras de semeadura direta do banco de sementes, determinados pelo método de flotação

\begin{tabular}{|l|r|r|r|r|r|r|r|c|}
\hline \multicolumn{1}{|c|}{ Nome científico } & \multicolumn{1}{c|}{$\mathrm{n}$} & \multicolumn{1}{c|}{ FA } & \multicolumn{1}{c|}{ DA } & AB & FRR & DER & ABR & IVI \\
\hline Pennisetum americanum & 101.400 & 0,80 & 2.028 & 2.535 & 50,63 & 73,80 & 28,11 & 152,54 \\
\hline Brassica rapa & 18.000 & 0,36 & 360 & 1.000 & 22,78 & 13,10 & 11,09 & 46,97 \\
\hline Amaranthus deflexus & 8.400 & 0,18 & 168 & 933 & 11,39 & 6,11 & 10,35 & 27,86 \\
\hline Digitaria horizontalis & 2.400 & 0,04 & 48 & 1.200 & 2,53 & 1,75 & 13,31 & 17,58 \\
\hline Cenchrus echinatus & 3.000 & 0,08 & 60 & 750 & 5,06 & 2,18 & 8,32 & 15,56 \\
\hline Eleusine indica & 2.400 & 0,06 & 48 & 800 & 3,80 & 1,75 & 8,87 & 14,42 \\
\hline Oxalis corniculata & 600 & 0,02 & 12 & 600 & 1,27 & 0,44 & 6,65 & 8,36 \\
\hline Rhynchelytrum repens & 600 & 0,02 & 12 & 600 & 1,27 & 0,44 & 6,65 & 8,36 \\
\hline Mimosa pigra & 600 & 0,02 & 12 & 600 & 1,27 & 0,44 & 6,65 & 8,36 \\
\hline \multicolumn{1}{|c|}{ Total } & 137.400 & 1,58 & 2748 & 9018,33 & 100 & 100 & 100 & 300 \\
\hline
\end{tabular}

$\mathrm{n}=$ número de indivíduos amostrados; $\mathrm{FA}=$ freqüência absoluta; $\mathrm{DA}=$ densidade absoluta; $\mathrm{AB}=$ abundância absoluta; $\mathrm{FRR}=$ freqüência relativa; $\mathrm{DER}=$ densidade relativa; $\mathrm{ABR}=$ abundância relativa; $\mathrm{IVI}$ = índice de valor de importância.

Tabela 4 - Parâmetros fitossociológicos das espécies identificadas na flora emergente sob sistema de semeadura direta

\begin{tabular}{|l|r|r|r|r|r|r|r|r|}
\hline \multicolumn{1}{|c|}{ Nome científico } & \multicolumn{1}{c|}{$\mathrm{n}$} & \multicolumn{1}{c|}{ FA } & \multicolumn{1}{c|}{ DA } & \multicolumn{1}{c|}{ AB } & \multicolumn{1}{c|}{ FRR } & \multicolumn{1}{c|}{ DER } & \multicolumn{1}{c|}{ ABR } & IVI \\
\hline Cenchrus echinatus & 1.820 & 1,00 & 36,40 & 36,40 & 17,36 & 36,31 & 27,05 & 80,72 \\
\hline Pennisetum americanum & 1.581 & 1,00 & 31,62 & 31,62 & 17,36 & 31,54 & 23,50 & 72,40 \\
\hline Eleusine indica & 731 & 0,60 & 14,62 & 24,36 & 10,42 & 14,58 & 18,11 & 43,11 \\
\hline Chamaesyce hirta & 435 & 0,84 & 8,70 & 10,36 & 14,58 & 8,68 & 7,70 & 30,96 \\
\hline Amaranthus deflexus & 290 & 0,50 & 5,80 & 11,60 & 8,68 & 5,79 & 8,62 & 23,09 \\
\hline Bidens pilosa & 45 & 0,26 & 0,90 & 3,46 & 4,51 & 0,90 & 2,57 & 7,98 \\
\hline Commelina benghalensis & 16 & 0,24 & 0,32 & 1,33 & 4,17 & 0,32 & 0,99 & 5,48 \\
\hline Spermacoce latifolia & 14 & 0,20 & 0,28 & 1,40 & 3,47 & 0,28 & 1,04 & 4,79 \\
\hline Nicandra physaloides & 16 & 0,18 & 0,32 & 1,78 & 3,13 & 0,32 & 1,32 & 4,77 \\
\hline Ipomoea grandifolia & 13 & 0,18 & 0,26 & 1,44 & 3,13 & 0,26 & 1,07 & 4,46 \\
\hline Croton sp. & 11 & 0,18 & 0,22 & 1,22 & 3,13 & 0,22 & 0,91 & 4,25 \\
\hline Euphorbia heterophylla & 11 & 0,18 & 0,22 & 1,22 & 3,13 & 0,22 & 0,91 & 4,25 \\
\hline Tridax procumbens & 11 & 0,16 & 0,22 & 1,38 & 2,78 & 0,22 & 1,02 & 4,02 \\
\hline Solanum americanum & 12 & 0,12 & 0,24 & 2,00 & 2,08 & 0,24 & 1,49 & 3,81 \\
\hline Portulaca oleracea & 2 & 0,04 & 0,04 & 1,00 & 0,69 & 0,04 & 0,74 & 1,48 \\
\hline Digitaria horizontalis & 1 & 0,02 & 0,02 & 1,00 & 0,35 & 0,02 & 0,74 & 1,11 \\
\hline Elephantopus mollis & 1 & 0,02 & 0,02 & 1,00 & 0,35 & 0,02 & 0,74 & 1,11 \\
\hline Diodia teres & 1 & 0,02 & 0,02 & 1,00 & 0,35 & 0,02 & 0,74 & 1,11 \\
\hline Ageratum conyzoides & 1 & 0,02 & 0,02 & 1,00 & 0,35 & 0,02 & 0,74 & 1,11 \\
\hline Total & 5.012 & 5,76 & 100,24 & 134,58 & 100,00 & 100,00 & 100,00 & 300,00 \\
\hline
\end{tabular}

$\mathrm{n}=$ número de indivíduos amostrados; $\mathrm{FA}=$ freqüência absoluta; $\mathrm{DA}=$ densidade absoluta; $\mathrm{AB}=$ abundância absoluta; $\mathrm{FRR}=$ freqüência relativa; $\mathrm{DER}=$ densidade relativa; $\mathrm{ABR}=$ abundância relativa; $\mathrm{IVI}$ = índice de valor de importância. 
sistemas de avaliação. O indice de similaridade de Sørensen foi de 0,35, interpretado como sendo baixa a similaridade entre o banco de sementes determinado pelo método de flotação e a flora emergente no sistema de semeadura direta.

Os coeficientes de correlação de Spearman entre a flora emergente e o banco de sementes determinado pelo método de flotação, para as principais espécies ocorridas no sistema de semeadura direta, são apresentados na Tabela 5 .

Tabela 5 - Coeficientes de correlação de Spearman entre o banco de sementes e a flora emergente, em relação ao número de indivíduos das principais espécies encontradas no sistema de semeadura direta

\begin{tabular}{|l|c|}
\hline \multicolumn{1}{|c|}{ Espécie } & Coeficiente de correlação \\
\hline Cenchrus echinatus & $0,035^{\text {ns }}$ \\
\hline Pennisetum americanum & $0,296^{\text {ns }}$ \\
\hline Eleusine indica & $0,884^{* *}$ \\
\hline Amaranthus deflexus & $0,453^{* *}$ \\
\hline
\end{tabular}

$\mathrm{ns}=$ não-significativo a $5 \% * *$ significativo a $1 \%$.

Amaranthus deflexus mostrou correlação significativa entre o banco de sementes e a flora emergente, com coeficiente de 0,453, no ambiente sob sistema de semeadura direta.

Eleusine indica apresentou correlação significativa no ambiente sob sistema de semeadura direta, com coeficiente de 0,884 entre a flora emergente e o banco de sementes determinado pelo método de flotação. Isso significa que $78 \%$ da flora emergente dessa espécie pode ser explicada pelo banco de sementes.

\section{Semeadura convencional (SSC)}

Banco de sementes (SSC) - No sistema de semeadura convencional foram encontradas quatro espécies diferentes, distribuídas em quatro familias, das quais três eram Dicotyledoneae e uma Monocotyledoneae. As espécies encontradas nas amostras de solo e as respectivas nomenclaturas estão apresentadas na Tabela 1. Os resultados dos indices fitossociológicos calculados, determinados pelo método de flotação no sistema de semeadura convencional, encontram-se na Tabela 6.

As espécies encontradas nas amostras do banco de sementes do sistema de semeadura convencional, em ordem de importância, foram Amaranthus deflexus, Brassica rapa, Portulaca oleracea e Commelina benghalensis. Observase, claramente, menor diversidade e riqueza de espécies no banco de sementes neste sistema em comparação com o sistema de semeadura direta, mais conservacionista, devido ao distúrbio no preparo do solo, perturbando mais intensamente o ambiente.

Flora emergente (SSC) - No sistema de semeadura convencional foram encontradas 14 espécies, distribuídas em nove famílias, das quais 10 espécies Dicotyledoneae e quatro Monocotyledoneae (Tabela 2). As famílias que apresentaram maior número de espécies foram: Poaceae (3), Asteraceae (3) e Euphorbiaceae (2). Os resultados dos indices fitossociológicos calculados estão apresentados na Tabela 7 .

As seis espécies que mais se destacaram pelo valor de importância foram Portulaca oleracea, Chamaesyce hirta e Amaranthus

Tabela 6 - Parâmetros fitossociológicos das espécies de sementes encontradas nas amostras de semeadura convencional do banco de sementes, determinados pelo método de flotação

\begin{tabular}{|l|r|r|r|r|r|r|r|r|}
\hline \multicolumn{1}{|c|}{ Nome científico } & \multicolumn{1}{c|}{$\mathrm{N}$} & $\mathrm{FA}$ & \multicolumn{1}{c|}{$\mathrm{DA}$} & \multicolumn{1}{c|}{ AB } & FRR & DER & \multicolumn{1}{c|}{ ABR } & IVI \\
\hline Amaranthus deflexus & 74.400 & 0,36 & 1.488 & 4.133 & 40,00 & 72,09 & 64,21 & 176,30 \\
\hline Brassica rapa & 27.600 & 0,50 & 552 & 1.104 & 55,56 & 26,74 & 17,15 & 99,45 \\
\hline Commelina benghalensis & 600 & 0,02 & 12 & 600 & 2,22 & 0,58 & 9,32 & 12,12 \\
\hline Portulaca oleracea & 600 & 0,02 & 12 & 600 & 2,22 & 0,58 & 9,32 & 12,12 \\
\hline \multicolumn{1}{|c|}{ Total } & 103.200 & 0,90 & 2064 & 6437 & 100 & 100 & 100 & 300 \\
\hline
\end{tabular}

$\mathrm{n}=$ número de indivíduos amostrados; $\mathrm{FA}=$ freqüência absoluta; $\mathrm{DA}=$ densidade absoluta; $\mathrm{AB}=$ abundância absoluta; $\mathrm{FRR}=$ freqüência relativa; $\mathrm{DER}=$ densidade relativa; $\mathrm{ABR}=$ abundância relativa; $\mathrm{IVI}$ = índice de valor de importância. 
Tabela 7 - Parâmetros fitossociológicos das espécies encontradas no sistema de semeadura convencional

\begin{tabular}{|l|r|r|r|r|r|r|r|r|}
\hline \multicolumn{1}{|c|}{ Nome científico } & \multicolumn{1}{c|}{$\mathrm{N}$} & \multicolumn{1}{c|}{ FA } & \multicolumn{1}{c|}{ DA } & \multicolumn{1}{c|}{ AB } & \multicolumn{1}{c|}{ FRR } & \multicolumn{1}{c|}{ DER } & \multicolumn{1}{c|}{ ABR } & \multicolumn{1}{c|}{ IVI } \\
\hline Portulaca oleracea & 4.244 & 1 & 84,88 & 84,88 & 19,16 & 54,32 & 49,36 & 122,83 \\
\hline Chamaesyce hirta & 2.285 & 1 & 45,70 & 45,70 & 19,16 & 29,25 & 26,57 & 74,98 \\
\hline Amaranthus deflexus & 953 & 0,96 & 19,06 & 19,85 & 18,39 & 12,20 & 11,54 & 42,13 \\
\hline Commelina benghalensis & 148 & 0,82 & 2,96 & 3,61 & 15,71 & 1,89 & 2,10 & 19,70 \\
\hline Euphorbia heterophylla & 71 & 0,60 & 1,42 & 2,37 & 11,49 & 0,91 & 1,38 & 13,78 \\
\hline Pennisetum americanum & 62 & 0,30 & 1,24 & 4,13 & 5,75 & 0,79 & 2,40 & 8,94 \\
\hline Cenchrus echinatus & 34 & 0,30 & 0,68 & 2,27 & 5,75 & 0,44 & 1,32 & 7,50 \\
\hline Ageratum conyzoides & 5 & 0,06 & 0,10 & 1,67 & 1,15 & 0,06 & 0,97 & 2,18 \\
\hline Eleusine indica & 3 & 0,06 & 0,06 & 1,00 & 1,15 & 0,04 & 0,58 & 1,77 \\
\hline Tridax procumbens & 3 & 0,04 & 0,06 & 1,50 & 0,77 & 0,04 & 0,87 & 1,68 \\
\hline Cyperus ferax & 2 & 0,02 & 0,04 & 2,00 & 0,38 & 0,03 & 1,16 & 1,57 \\
\hline Ipomoea grandifolia & 1 & 0,02 & 0,02 & 1,00 & 0,38 & 0,01 & 0,58 & 0,98 \\
\hline Elephantopus mollis & 1 & 0,02 & 0,02 & 1,00 & 0,38 & 0,01 & 0,58 & 0,98 \\
\hline Bidens pilosa & 1 & 0,02 & 0,02 & 1,00 & 0,38 & 0,01 & 0,58 & 0,98 \\
\hline \multicolumn{1}{|c|}{ Total } & 7.813 & & 156,26 & 171,98 & 100,00 & 100,00 & 100,00 & 300,00 \\
\hline
\end{tabular}

$\mathrm{n}=$ número de indivíduos amostrados; $\mathrm{FA}=$ freqüência absoluta; $\mathrm{DA}=$ densidade absoluta; $\mathrm{AB}=$ abundância absoluta; $\mathrm{FRR}=$ freqüência relativa; $\mathrm{DER}=$ densidade relativa; $\mathrm{ABR}=$ abundância relativa; IVI = índice de valor de importância.

deflexus, que respondem juntas por $95,8 \%$ do total de emergências, em seguida, ficaram as espécies Commelina benghalensis, Euphorbia heterophylla e Pennisetum americanum.

O maior tamanho do banco de sementes de plantas daninhas determinado pelo método de flotação, em relação à flora emergente, se deve à dormência inerente às sementes. Isso pode ter acontecido com a espécie Brassica rapa, única que ocorreu no banco de sementes e não na flora emergente.

\section{Correlações entre o banco de sementes e a flora emergente (SSC)}

Comparando a similaridade entre o banco de sementes determinado pelo método de flotação e a flora emergente do sistema de semeadura convencional, foram encontradas 15 espécies entre os dois. Na flora emergente ocorreram 14 espécies e, nas amostras do banco de sementes de semeadura convencional, quatro. Ocorreram três espécies comuns entre o banco de sementes determinado pelo método de flotação e a flora emergente do sistema de semeadura convencional. O indice de similaridade de Sørensen calculado por meio desses dados foi de 0,33, indicando baixa similaridade entre o banco de sementes determinado pelo método de flotação e a flora emergente do sistema de semeadura convencional.

Esses resultados, tanto em ambiente sob semeadura direta como convencional, condizem com estudo realizado por Chikoye \& Ekeleme (2001) para correlacionar banco de sementes e flora emergente, os quais obtiveram fracas correlações, tendo como indicativo baixo indice de similaridade de Sørensen. Diferenças na composição das espécies entre a flora emergente e o banco de sementes podem ser atribuídas a vários fatores, como tipo de cultura e manejo do solo e de plantas daninhas (Mayor \& Dessaint, 1998). Além disso, certas plantas daninhas parecem ter mais sucesso em áreas com culturas especificas (Terry, 1981). Cardina et al. (1991) relataram que o preparo convencional do solo diminui a diversidade e riqueza de espécies, comparado com sistemas mais conservacionistas.

Os coeficientes de correlação de Spearman entre a flora emergente e o banco de sementes determinado pelo método de flotação, em relação ao número das principais espécies ocorridas no sistema de semeadura convencional, são apresentados na Tabela 8 . 
Tabela 8 - Coeficientes de correlação entre o banco de sementes e a flora emergente das principais espécies, em relação ao número de indivíduos encontrados no sistema de semeadura convencional

\begin{tabular}{|l|c|}
\hline \multicolumn{1}{|c|}{ Espécie } & Coeficiente de correlação \\
\hline Portulaca oleracea & $0,054^{\mathrm{ns}}$ \\
\hline Amaranthus deflexus & $0,611^{* *}$ \\
\hline Commelina benghalensis & $-0,179^{\mathrm{ns}}$ \\
\hline
\end{tabular}

$\mathrm{ns}=$ não-significativos a $5 \% * *$ significativos a $1 \%$.

O maior coeficiente de Amaranthus deflexus $(0,611)$ ocorreu entre a flora emergente e o banco de sementes no ambiente sob semeadura convencional, o que leva à interpretação de que $37,0 \%$ da flora emergente dessa espécie pode ser explicada pelo banco de sementes dessa espécie, quando determinado pelo método de flotação.

A análise dos coeficientes de correlação corrobora a baixa relação entre flora emergente e banco de sementes para as principais plantas daninhas ocorrentes nos ambientes de estudo. De acordo com os resultados, houve correlação entre o banco de sementes e a flora emergente para a espécie Amaranthus deflexus, nos sistemas de semeadura direta e convencional, e para a espécie Eleusine indica, no sistema de semeadura direta. Quanto às demais espécies encontradas, essa correlação não foi significativa.

Proporcionalmente, no sistema de semeadura direta, entre as 23 espécies diferentes encontradas nos dois ambientes, no solo e na flora emergente, houve $8,69 \%$ de espécies correlacionadas ao seu banco de sementes. No sistema de semeadura convencional, do total de 15 espécies diferentes encontradas, essa porcentagem foi de $6,66 \%$.

Portanto, dado o grande número de fatores, bióticos e abióticos, que influenciam a baixa relação entre o banco de sementes e o estabelecimento da flora de plantas daninhas em ambientes de culturas anuais, são necessárias pesquisas adicionais por maior periodo de tempo para obter maior acurácia na predição de infestações, tendo como parâmetro o banco de sementes de plantas daninhas do solo.

\section{LITERATURA CITADA}

ALMEIDA-CORTEZ, J. S. Dispersão e banco de sementes. In: FERREIRA, A. G.; BORGUETTI, F. Germinação: do básico ao aplicado. Porto Alegre: Artmed, 2004. p. 227-235.

BLANCO, H. G.; ARÉVALO, R. A.; BLANCO, F. M. G. Distribuição mensal da emergência de seis ervas daninhas em solos com e sem cultivos. Planta Daninha, v. 12, n. 2 , p. 78-83, 1994.

BOOTH, B. D.; MURPHY, S. D.; SWANTON, C. J. Weed ecology in natural and agricultural systems. Guelph: Paperback, 2003. 298 p.

CARDINA, J.; REGNIER, E.; HARRISON, K. Long-term tillage effects on seed banks in three Ohio soils. Weed Sci., v. 39 , p. 186-194, 1991.

CARDINA, J.; SPARROW, D. H.; Mc COY, E. L. Spatial relationships between seed bank and seedling populations of common lambsquarter (Chenopodium album) and annual grasses. Weed Sci., v. 44, p. 298-308, 1996.

CARMONA, R. Problemática e manejo de bancos de sementes de invasoras em solos agrícolas. Planta Daninha, v. 10, n. $1 / 2$, p. $5-16,1992$.

CHIKOYE, D.; EKELEME, F. Weed flora and soil seedbanks in fields dominated by Imperata cylindrica in the moist savannah of West Africa. Weed Res., v. 41, p. 475490, 2001

GRANATOS, F. L.; TORRES, L. G. Seed bank and other demographic parameters of broomrape (Orobanche crenata Forsk) populations in faba bean (Vicia faba L.). Weed Res., v. 33, n. 4, p. 319-327, 1993

KISSMAN, K. G.; GROTH, D. Plantas infestantes e nocivas. 2.ed. São Paulo: Basf, 1997. 825 p.

KISSMAN, K. G.; GROTH, D. Plantas infestantes e nocivas. 2.ed. São Paulo: Basf, 1999. 978 p.

KISSMAN, K. G.; GROTH, D. Plantas infestantes e nocivas. 2.ed. São Paulo: Basf, 2000. 726 p.

LAMPRECHT, H. Silvicultura nos trópicos: ecossistemas florestais e respectivas espécies arbóreas - possibilidades e métodos de aproveitamento sustentado. Tradução de: ALMEIDA-SEDAS, G.; CALCAGNOTTO, G. Rossdorf: TZ-Verl.-Ges., 1990. 343 p.

LORENZI, H. Manual de identificação e controle de plantas daninhas: plantio direto e convencional. 5.ed. Nova Odessa: Instituto Plantarum, 2000. 384 p.

Planta Daninha, Viçosa-MG, v. 26, n. 3, p. 521-530, 2008 
MARTINS, C. C.; SILVA, W. R. Estudos de banco de sementes do solo. Inf. Abrates, v. 4, n. 1, p. 49-56, 1994.

MAYOR, J. P.; DESSAINT, F. Influence of weed manegement strategies on soil seedbank diversity. Weed Res., v. 38, p. 95-195, 1998.

PEREIRA, F. A. R.; VELINI, E. D. Sistemas de cultivo no cerrado e dinâmica de populações de plantas daninhas.

Planta Daninha, v. 21, n. 3, p. 355-363, 2003.

PITELLI, R. A. Estudos fitossociológicos em comunidades infestantes de agroecossistemas. J. Conserb., v. 1, n. 2, p. 17, 2000 .
ROBERTS, H. A.; FEAST, P. M. Emergence and longevity of seeds of annual weeds in cultivated and undisturbed soil. J. Appl. Ecol., v. 12, n. 4, p. 316-324, 1972.

STEEL, R. G. D.; TORRIE, J. H. Principles and procedures of statistics: a biometrical approach. New York: McGraw-Hill, 1980. 633 p.

TERRY, P. J. Weeds and their control in the Gambia. Trop. Pest Manag., v. 27, n. 1, p. 44-52, 1981.

ZELAYA, I. A.; OVEN, M. D. K.; PITTY, A. Effect of tillage and environment on weed population dynamics in the dry tropics. Ceiba, v. 38, n. 2, p. 123-135, 1997. 